\title{
El sistema judicial y su rol en las políticas públicas: una mirada a las políticas globales ${ }^{1}$
}

\section{The judicial system and its role in public policies: a look at global policies}

\author{
José Ignacio Torres Justiniani \\ Universidad Virtual del Estado de Guanajuato (México) \\ ORCID: https://orcid.org/0000-0002-3216-219X \\ torres0112@hotmail.com
}

\section{NOTA BIOGRÁFICA}

Doctor en Políticas Públicas por el Instituto de Investigaciones Económicas y Empresariales de la Universidad Michoacana de San Nicolás de Hidalgo (UMSNH), Maestro en Derecho con Opción en Humanidades por la División de Estudios de Posgrado de la Facultad de Derecho y Ciencias Sociales de la UMSNH, Maestro en Gestión Pública Aplicada por el Instituto Tecnológico y de Estudios Superiores de Monterrey, Licenciado en Derecho por la UMSNH. Profesor División de Estudios de Posgrado de la Facultad de Derecho y Ciencias Sociales de la UMSNH.

\section{RESUMEN}

La intervención judicial en las políticas públicas y su ciclo es un tema poco estudiado en la disciplina de las políticas. La forma en que interactúan los anteriores, así como sus alcances y límites aún esperan ser estudiados y desarrollados. Por lo tanto, el presente trabajo tiene como objetivo analizar, en su primera parte, las cualidades y características del sistema judicial, sobre todo aquellas que son relevantes para su intervención en las políticas. En la segunda parte, se analizan el ciclo de políticas así como casos reales que tienen relación con cada una de las etapas de este. En la tercera parte se exponen las características principales de las políticas públicas globales y la forma en que la intervención judicial puede presentarse en estas. Finalmente se ofrecen breves conclusiones.

\section{PALABRAS CLAVE}

Sistema judicial; políticas públicas; políticas públicas globales; ciclo de políticas.

\begin{abstract}
Judicial intervention in public policy and its cycle is a subject little studied in the discipline of policies. The way in wich the previous ones interact, as well as their scope and limits, still await study and development. Therefore, the present work aims to analyze, in its first part, the qualities and characteristics of the judicial system, especially those that are relevant for its intervention in policies. In the second part, the policy cycle is analyzed as well as real cases that are related to each of its stages. The third part presents the main charactaristics of global public policies and the way in wich judicial intervention can be presented in them, Finally, brief conclusions are offered.
\end{abstract}

\section{KEYWORDS}

Judicial system; public policy; global public policy; policy cycle.

\footnotetext{
1 Agradezco los valiosos comentarios emitidos por los evaluadores así como de los editores para la elaboración de este trabajo.
} 


\section{SUMARIO}

1. INTRODUCCIÓN. 2.1. FACULTADES EXCLUSIVAS DEL SISTEMA JUDICIAL. 2.2. RELACIÓN ENTRE POLÍTICAS PÚBLICAS Y SISTEMA JUDICIAL. 3. POLÍTICAS PÚBLICAS GLOBALES. 3.1. DE LA GOBERNANZA A LA NUEVA GOBERNANZA. 4. DEFINICIÓN Y CARACTERÍSTICAS DE LAS POLÍTICAS PÚBLICAS GLOBALES. 4.1. POLÍTICAS PÚBLICAS GLOBALES E INTERVENCIÓN JUDICIAL. 5. CONCLUSIONES.

\section{INTRODUCCIÓN}

El objetivo del presente trabajo de corte teórico y exploratorio, es delinear los posibles alcances de la participación judicial en la disciplina de políticas públicas globales, así como incluir a los tribunales internacionales como actores de políticas públicas globales. Para fundamentar lo anterior, es necesario señalar primero que se trata de una disciplina muy nueva, razón por la cual se ofrecerá en este trabajo un breve estado del arte, así como un análisis de la situación actual que guarda esta disciplina, por otro lado, en lo referente al análisis de la influencia judicial en las políticas, se parte del supuesto de que esta se ha desarrollado sobre todo desde el campo de la ciencia política (judicial politics), pero no de las políticas públicas, por lo que resulta aún un campo poco explorado en la disciplina, lo que por supuesto repercute en los efectos y alcances que puede llegar a tener en la disciplina global antes señalada.

La forma en que los miembros de sistema judicial participan e inciden en las políticas ha sido ampliamente estudiado por la ciencia política, principalmente a partir de lo que se conoce como «judicial politics». De acuerdo con Azul Aguiar (2019) judicial politics, «(...) es definida entonces como la participación cada vez más activa de las cortes en la creación, expansión, pero también restricción de políticas, derechos y libertades» (p. 27). Esta perspectiva se enfoca principalmente en la actitud de las cortes y los miembros del sistema judicial, análisis que desde el punto de vista teórico se ha desarrollado a partir de tres grandes enfoques: el legalista, el actitudinal-ideológico y el estratégico o neoinstitucionalista racional (Aguiar, 2019, p. 35). Estos enfoques en general analizan la actitud y comportamiento de los jueces desde la ciencia política, es decir, analizan por qué los jueces toman ciertas decisiones o qué los motiva para actuar de cierta manera, sin embargo, estos enfoques no analizan los efectos e intensidad de las decisiones judiciales en las políticas y su ciclo de forma específica, lo que representa un área de oportunidad. En otras palabras, lo que le interesa a la «política judicial», es determinar o comprender cómo y por qué las cortes, a través de sus miembros, actúan como lo hacen, qué los motiva a tomar ciertas decisiones y si estas decisiones son susceptibles de ser mensajes a tomar en cuenta por los actores del ámbito político.

En consecuencia, judicial politics se enfoca y preocupa por el cómo y por qué de tal o cual decisión a partir de la perspectiva de las cortes y sus miembros, pero no así de las consecuencias de estas decisiones en lo que a políticas públicas se refiere, y, mucho menos, los efectos de las decisiones de tribunales internacionales en las políticas.

Por lo tanto, antes de analizar los efectos del sistema judicial en las políticas globales, explicaré la relación de las primeras con las políticas públicas, para una vez delineadas, pasar al tema global y sus posibles alcances. Así, en la primera parte de este trabajo describo la relación entre políticas y sistema judicial, delineando sus características y facultades exclusivas, después, analizo la definición de políticas y su ciclo, utilizando en cada etapa un caso judicial real para ejemplificar los efectos. Posteriormente, se analizan las políticas públicas globales, sus características y posible relación con la intervención judicial, ello mediante el estudio de casos paradigmáticos resueltos por un tribunal internacional, con lo cual, se pretende fundamentar el por qué se debe incluir a estos actores a la disciplina de políticas públicas globales. Finalmente, se ofrecen algunas conclusiones sobre la relación e importancia de la participación judicial en las políticas globales.

\section{RELACIÓN ENTRE POLÍTICAS PÚBLICAS Y SISTEMA JUDICIAL}

En la disciplina de políticas públicas es poco común concebir al poder judicial como un actor preponderante, sin embargo, su influencia en la disciplina puede tener un profundo impacto. La relación entre políticas y sistema judicial se explica a partir de dos aspectos fundamentales: en primer lugar, las facultades exclusivas que corresponden al sistema judicial y, segundo, el control constitucional cada vez más imperante en diversos países, es decir, la creciente ola de constitucionalismo global. Ambas permiten explicar el potencial 
de influencia del sistema judicial en las políticas en la actualidad y, como expondré más adelante, su relación con las políticas públicas globales. Antes de analizar lo anterior, merece la pena hacer una precisión respecto a lo que se entiende como «poder judicial».

Ahora, al referirnos a poder judicial o sistema judicial, se hace alusión no al poder judicial de un país o sistema de gobierno en abstracto, sino a las facultades depositadas en ciertos esquemas de funcionamiento de control constitucional que varían dependiendo del país y su diseño institucional, las cuales en general se pueden presentar en tres formas: la primera a partir de una Corte Suprema que se sitúa en la cúspide de la jerarquía constitucional, así, el análisis de las normas y su constitucionalidad esta restringida solo a este órgano. La segunda es a partir de una Corte Constitucional o Tribunal Constitucional, el cual se sitúa «fuera» de la jerarquía judicial, para analizar solo cuestiones relativas a controversias constitucionales. Finalmente, existe una forma «difusa», en la cual cualquier tribunal puede señalar la inconstitucionalidad de las normas, como en el caso estadounidense (Aguiar, 2019, p. 29).

Lo anterior quedará más claro en el aparatado siguiente en el cual se abordarán las facultades exclusivas del sistema judicial. Debemos tener en claro que estas facultades varían de acuerdo con el tipo de sistema de control constitucional. Lo que quiero resaltar, es que la forma en que el poder judicial afecta a las políticas se presenta de forma más clara y evidente en controles constitucionales, es decir, en las jerarquías más altas (Corte Suprema) o, en un tribunal constitucional, sin embargo, esto no quiere decir que los tribunales de menor jerarquía (a excepción del sistema estadounidense) no afecten a las políticas y su ciclo, sino que lo hacen de una forma menos profunda y dramática.

\subsection{Facultades exclusivas del sistema judicial}

En cuanto a las facultades exclusivas del sistema judicial, es necesario comprender que este tiene específicas tareas y atribuciones otorgadas por el sistema constitucional (constitución), en esencia, tiene la función de «intérprete último de la constitución y garante del orden constitucional» (Carmona, 2007, p. 175), esto quiere decir, que ante cualquier controversia sobre el contenido de cualquier norma o política pública, el que tendrá la última palabra para resolver el problema es el sistema judicial, así, a este último corresponde establecer los márgenes y fronteras sobre las cuales las políticas públicas deberán diseñarse e implementarse. Lo anterior se explica mejor a partir de la definición de Fix-Zamudio sobre los tribunales constitucionales, que se entienden como «aquellos que con independencia de su encuadramiento, dentro o fuera del poder judicial, deciden en última instancia sobre la interpretación definitiva de los principios, valores o normas fundamentales» (Fix-Zamudio, 2002, p. 212). Es decir, estos tribunales son los que tienen la capacidad y atribución de.

Interpretar la legalidad ordinaria de acuerdo con la Constitución y con arreglo a su sentido lógico y actual, de tal suerte que (...) se dote de seguridad a todo el ordenamiento, garantizando, en último término, el principio constitucional de igualdad en la aplicación de la ley en todo el territorio nacional (Celeste, 2013, p. 78).

En esencia, el poder judicial posee la capacidad de establecer los límites y fronteras de actuación de los gobernantes, de determinar si las políticas por ellos diseñadas e implementadas se ajustan a la normativa legal vigente, y con ello, a lo que la sociedad espera de ellas, de tal suerte que las políticas están sujetas en última instancia al escrutinio de la sociedad a través del sistema judicial.

La capacidad de influencia del sistema judicial en las políticas se comprende mejor a partir de sus facultades exclusivas, tendientes en cuatro efectos: 1. Vetar o reafirmar decisiones. Esta consiste en determinar si una política cumple o no con la normativa vigente y, en consecuencia, vetar la totalidad, una parte o, en caso de que no exista inconveniente, reafirmar la política en cuestión. 2. Actor proactivo. Al resolver una controversia sometida a su consideración relacionada a una política pública, el poder judicial envía un mensaje a los actores de la política, ya que ha establecido con su decisión o resolución, una forma específica en la cual debe concebirse, entenderse y explicarse la política en particular. 3. Árbitro imparcial. Se parte del supuesto de que el sistema judicial posee una determinada autonomía que le permite resolver las controversias relacionadas a las políticas de forma objetiva, acudiendo solo a lo establecido por la normativa vigente, así, las cuestiones de corte político o de oportunismo electoral quedan fuera del análisis para determinar los alcances de la política. 4. Representante de la sociedad. El poder judicial otorga a los sujetos o comunidades una oportunidad sin precedentes para ingresar ciertos problemas a la agenda, problemas que de otra forma quedarían fuera de la atención gubernamental, como por ejemplo demandas de pueblos originarios, 
falta de medicamentos o distribución de ciertos beneficios en una cierta política, etc., así, el poder judicial permite que cuestiones que hayan sido dejadas de lado, por cualquier razón, puedan ser retomadas con el mandato del órgano judicial, en esencia, se trata de la judicialización de las políticas, la capacidad para exigir su eficacia.

Las facultades y atribuciones exclusivas del sistema judicial nos permiten comprender mejor la importancia del segundo aspecto fundamental: el creciente constitucionalismo global (Miranda, 2018; Ackerman, 2006; Fernández, 1999; Cervantes, 1996). Este factor se refiere a una creciente adopción de sistemas de corte constitucional, es decir, países que han decidido adoptar como andamiaje de su sistema jurídico y social un esquema de control constitucional a partir de un texto fundamental (Constitución) que establece las fronteras y márgenes bajo los cuales se rige su estado de derecho, entendiendo mínimamente por este último la sujeción de todos a las normas vigentes².

A partir de la caída de la Unión Soviética, de 188 países miembros de Organización de Naciones Unidas (ONU) en aquel momento, $56 \%$ de estos realizó reformas, adoptando el $70 \%$ constituciones totalmente nuevas (Cepeda y Montealegre, 2007, p. 10). Así, para el año 2000, al menos 92 países han integrado en su sistema jurídico cartas de derechos fundamentales, de los cuales, al menos 36 países han creado un modelo de control constitucional centralizado en una Corte Constitucional (Cepeda y Montealegre, 2007, p. 11). Por lo tanto, estos países establecen como centro de su estructura política un andamiaje constitucional que siguiendo a Jorge Carpizo (Carpizo, 2009, pp. 749-750) puede contener las siguientes características y atribuciones: a) Controlar las normas generales, sin importar el poder constituido secundario que las expida; se examina si estas son compatibles con la Constitución, y si el tribunal considera que no lo son, anula dicha norma general con efectos erga omnes; b) Controlar la constitucionalidad de los tratados internacionales que pasan a ser parte del orden jurídico interno; c) Interpretar la Constitución, estableciendo sus propios parámetros interpretativos, con lo cual señala el marco jurídico y político de la propia actuación de las autoridades, construyendo juicios de valor que, sin duda alguna, implican decisiones políticas, lo cual queda claro especialmente en la protección de los derechos humanos; d) Resolver conflictos constitucionales y políticos entre los órganos o poderes secundarios; e) Adoptar definiciones políticas y sociales que impactan en la sociedad en temas tales como el aborto, la eutanasia y el principio de no discriminación, entre otras.

Por lo tanto, el sistema judicial, vía el orden constitucional -garantizado por los tribunales constitucionales-, contiene, delimita, enmarca, restringe y amplia la realidad política, social, cultural de la sociedad. Derivado de las dos características fundamentales del sistema judicial antes analizadas, es posible anticipar el efecto enorme que tiene este poder en la disciplina de políticas, sin embargo, considero necesario analizar brevemente qué son las estas últimas y su clico, para así tener una idea más clara de la influencia que intento señalar.

\subsection{Relación entre ciclo de políticas y sistema judicial}

Antes de analizar la relación entre ciclo de políticas y sistema judicial, es necesario definir la disciplina. La definición de políticas públicas es tan extensa y diversa como autores se consulte, por ello, para ser breve en el análisis, acudo a la obra de Raúl Velázquez, quien después de realizar un extenso estudio sobre la diversidad de definiciones, llega a la siguiente propuesta:

Política pública es un proceso integrador de decisiones, acciones, inacciones, acuerdos e instrumentos, adelantado por autoridades públicas con la participación eventual de los particulares, y encaminado a solucionar o prevenir una situación definida como problemática. La política pública hace parte de un ambiente determinado del cual se nutre y al cual pretende modificar o mantener (Velásquez, 2009, p. 156).

La definición anterior nos ofrece una visión clara y manejable sobre las políticas. Por ejemplo, nos permite resaltar al menos tres aspectos fundamentales sobre la disciplina: primero, que se requiere siempre de

\footnotetext{
2 De acuerdo con la Organización de las Naciones Unidas, estado de derecho es: «un principio de gobernanza en el que todas las personas, instituciones y entidades, públicas y privadas, incluido el propio Estado, están sometidas a leyes que se promulgan públicamente, se hacen cumplir por igual y se aplican con independencia, además de ser compatibles con las normas y los principios internacionales de derechos humanos. Asimismo, exige que se adopten medidas para garantizar el respeto de los principios de primacía de la ley, igualdad ante la ley, separación de poderes, participación en la adopción de decisiones, legalidad, no arbitrariedad, y transparencia procesal y legal» (ONU, 2020).
} 
la participación del Estado, de lo contrario no podríamos estar en presencia de una política, segundo, que se puede presentar la intervención de agentes privados en sus diversas dimensiones, es decir, la participación de agentes no estatales en la construcción de las políticas. Lo anterior es importante, ya que, como expondré más adelante, uno de los retos de la disciplina en su versión global, es que hay múltiples actores además del Estado que inciden de forma determinante, como por ejemplo organizaciones intergubernamentales (Banco Mundial, Fondo Monetario Internacional, Organización Mundial de Comercio, etc.), organizaciones no gubernamentales (Amnistía internacional, Green Peace, Human Rights Watch, etc.), entre otros. En tercer lugar, la política se reconoce como parte de un ambiente determinado del cual se nutre, es decir, este ambiente o, status quo, es lo que en esencia determina la capacidad de actuación del sistema judicial, ya que se espera que este último actúe de acuerdo con las normas vigentes, así como los más altos estándares en materia de derechos humanos al formular sus criterios.

En cuanto a la forma en que se construyen las políticas, existe en la academia poco consenso al respecto, por lo general se adopta lo que se llama ciclo de políticas públicas, el cual no esta exento de críticas, al respecto, autores como Michael Howlett, Diane Stone, Simon Maxwell y Michael Keating, consideran por ejemplo que este tipo de análisis encubre la complejidad inherente en su construcción, así mismo, critican la aparente armonía que retrata el ciclo en contraste con lo que parece ser una realidad más caótica en la creación de las políticas (Howlett, 2019; Stone, Maxwell y Keating, 2001, p. 10). Sin embargo, las ventajas de contar con un ciclo como método de análisis, también ha sido reconocida por varios autores (Everett, 2003; Dye, 2013; Birkland, 2015), en particular, porque permite conocer mejor los elementos distintivos al interior de cada una de las etapas, lo que facilita su estudio de forma «seccionada» y más detallada.

Al igual que en el caso de la definición, no existe un único ciclo o etapas, sino que estas varían de acuerdo con el autor que se consulte ${ }^{3}$. Afortunadamente, autores como Arías y Herrera (2012) se han dado a la tarea de realizar un análisis de frecuencia y agrupamiento a partir de la obra de catorce autores especializados y su ciclo propuesto, llegando a cuatro etapas más utilizadas, consistentes en: 1. Definición del problema, 2. Diseño de la política, 3. Implementación y 4. Seguimiento y evaluación. Estas cuatro etapas podríamos decir, reducen al máximo el ciclo de las políticas, sin embargo, debido a los efectos del sistema judicial, considero necesario incluir otra etapa: la formación o ingreso a la agenda.

Contar con la etapa de formación o ingreso a la agenda como etapa individual es importante para determinar los efectos de la intervención judicial, ya que derivado de las facultades exclusivas ya mencionadas, el sistema judicial permite a diversos actores (desde personas particulares hasta organizaciones no gubernamentales) intentar ingresar sus problemas a la agenda, así, analizar esta etapa en particular es capital para comprender los efectos. Por lo tanto, considero que es mejor contar con un ciclo de cinco etapas: 1 . Formación o ingreso a la agenda, 2. Definición del problema, 3. Diseño de la política, 4. Implementación y 5 . Seguimiento y evaluación. A continuación, analizaré brevemente cada una de las etapas y su relación con el sistema judicial.

Formación e ingreso en la agenda. De acuerdo con Birkland (2015), formar la agenda significa en pocas palabras lograr la atención del gobierno. En esta etapa es importante comprender que existen múltiples actores en el entorno social y político, quienes intentan posicionar ante la sociedad, así como el gobierno su propia definición del problema, así como su propia definición de la realidad y, por ende, su propuesta sobre la mejor forma de resolverlo. Se suele dividir a la agenda en dos partes, la agenda pública y la agenda gubernamental (Casar y Maldonado, 2010, citado por Arellano y Blanco, 2013, p. 41). La primera da cuenta de los problemas de moda en la sociedad, de aquellos a los que se tiene más exposición en los medios, redes sociales, etc., la segunda se refiere solo a aquellos problemas que ya han sido seleccionados por el gobierno y sobre los cuales pretende actuar y, por ello, dotar de recursos. Aquí es importante señalar que no es que existan problemas en «abstracto» allá afuera, sino que estos son construidos por diversos actores para impulsar su agenda e intereses.

3 Por ejemplo, Lasswell, en su obra The Decision Process de 1956, identifica siete etapas: 1. Inteligencia, 2. Promoción, 3. Prescripción, 4. Invocación, 5. Aplicación, 6. Impacto y, 7. Evaluación (Parsons, 2007, p. 112). Por su parte, Eugene Bardach, identifica ocho pasos: 1. Definir el problema, 2. Recabar evidencia, 3. Construir las alternativas, 4. Seleccionar los criterios, 5. Proyección de resultados, 6. Confrontar los costos, 7. Decidir, 8. Contar la historia (Bardach, 2012). Hogwood y Gunn, en su obra Policy Analysis for the Real World de 1984, presentan nueve etapas: 1. Decidirse a decidir (búsqueda de problemáticas o definición de la agenda); 2 . Decidir cómo decidir (filtración de problemáticas); 3. Decidir problemáticas; 4. Pronóstico; 5 . Establecer objetivos y prioridades; 6 . Analizar opciones; 7. Implementación, seguimiento y control de las políticas públicas; 8. Evaluación y Revisión; 9. Mantenimiento, sucesión y terminación de las políticas públicas (Parsons, 2007, pp. 112-113). Luis Aguilar, por otro lado, señala siete pasos: 1. Formación de la agenda, 2. Definición del problema público, 3. Hechura o formulación de la política, 4. Decisión o selección entre opciones, 5. Comunicación política, 6. Implementación de la política y 7. Evaluación de la política (Aguilar, 2010, p. 34). 
Ahora ¿cómo se relaciona esta etapa con el sistema judicial? Una de las facultades más representativas del poder judicial, como ya se explicó antes, es que puede imponer una decisión (vetar, reafirmar, modificar, etc.) a partir del análisis que se somete a su consideración, así, diversos actores tienen la oportunidad de reclamar ante el poder judicial violaciones que ellos consideren han sido perpetradas por los actores de las políticas, por ejemplo, al dejarlos fuera de un cierto beneficio (como un medicamento, tratamiento médico, sistema de alcantarillado, alumbrado público, etc.) o, al señalar que una política en cuestión es discriminatoria o ilegal, buscando con ello corregirla. Así, en lugar de acudir a los legisladores o representantes del poder ejecutivo, lo que sería en muchos casos una pérdida de tiempo valioso, se puede reclamar por la vía judicial la corrección de la política. Veamos un ejemplo real de influencia judicial en dos casos judiciales: Perú y Chile.

Los casos en cuestión tienen que ver con la aplicación de una política pública en materia de salud, específicamente la introducción o no de la pastilla del día después al catálogo de salud. La cuestión es que dicha política que incluía la píldora detonó en los grupos conservadores de corte religioso, una demanda de inconstitucionalidad ante el Tribunal Constitucional chileno, argumentando que la píldora tenía efectos abortivos, lo que iba en contra de las leyes vigentes. Al final, el Tribunal consideró que no se podía tener certeza sobre los efectos de la píldora, por lo que decidió eliminar dicha pastilla de la política de salud (Corilloclla, 2009, p. 9). En el caso peruano también se interpuso un recurso ante la Corte Suprema, pero en este caso, fue promovido por un grupo de mujeres que consideraban que la política (que incluía la píldora) era discriminatoria, pues la pastilla no se entregaba de forma gratuita, lo que dejaba a mujeres de escasos recursos sin la posibilidad de adquirirla. En este caso, la Corte determinó que la política, como estaba diseñada, resultaba discriminatoria, y ordenó a los actores encargados de la política, modificar lo que fuera necesario para distribuirla de forma gratuita (Corilloclla, 2009, p. 9).

Lo que ambos casos permiten observar, es que la intervención judicial posibilita a diversos actores el ingresar sus temas a la agenda, en el caso chileno, los grupos conservadores lograron imponer su visión sobre la píldora (sobre supuestos efectos abortivos) lo que posibilitó que la solución por ellos propuesta (eliminar la píldora de la política) fuera validada por el Tribunal. En el caso peruano, la intervención judicial también permitió ingresar el tema en la agenda, en este caso, de un grupo vulnerable (mujeres de escasos recursos), lo que permitió que la política, considerada en un inicio discriminatoria, se corrigiera vía judicial. Analicemos a continuación la segunda etapa del ciclo y los efectos del sistema judicial.

La etapa de definición del problema, siguiendo a David Dery (2000), posee dos máximas:

La primera máxima de la definición del problema es reconocer que los problemas no existen «allá afuera», no son entidades abstractas en su propio derecho, sino construcciones analíticas. La segunda máxima, sugiere que las definiciones a problemas en el contexto de la práctica deben responder a los criterios de factibilidad y valor, o de progreso. Semejante análisis de políticas es definido como «crear y elaborar problemas que merece la pena resolver» (Dery, 2000, p. 40).

Por lo tanto, definir el problema es ante todo reconocer los límites, las capacidades y actuar en consecuencia, así, los hacedores de la política, para bien o para mal, se enfocan en aquellos problemas que consideran, pueden resolver con los recursos que poseen. En esta etapa, la intervención judicial se presenta sobre todo como un elemento que permite a los actores de las políticas reformular o mantener su concepción del problema, es decir, el poder judicial obliga mediante su resolución a contemplar un aspecto no tomado en cuenta en el problema y su diseño. Al respecto, los casos antes mencionados sirven como ejemplo de los efectos judiciales, en el caso peruano, la definición del problema de la política relativa a la píldora no contemplaba la entrega gratuita a la población de escasos recursos, lo que en esencia, implica que su definición del problema estuvo mal planteada, o al menos, así se percibió por la población objetivo de la política. Otro caso que puede ejemplificar muy bien los efectos en esta etapa es el caso de acceso a tratamiento médico de Perú. En este, una persona infectada por VIH/SIDA, interpuso un recurso judicial ante la negativa del Estado para brindarle atención médica, pues argumentaba que la atención a este padecimiento se podía dar de forma gratuita solo a las mujeres embarazadas que estuvieran infectadas, ello con el objetivo de prevenir el contagio del bebé. Ante esta situación, el tribunal determinó lo siguiente:

El Tribunal reconoce que en la implementación de políticas públicas destinadas a satisfacer derechos sociales como la salud, que requiere de prestaciones de servicios, es necesario que se destine un presupuesto determinado. Sin embargo, sostiene que el hecho que este tipo de 
derechos tengan una satisfacción progresiva no significa que el Estado deba tener una actitud pasiva y que se deberían tener plazos razonables para satisfacerlos. El Tribunal ordena que el Estado brinde los servicios de salud al demandante, quien no cuenta con los medios económicos para cubrir sus tratamientos y establece que no se debería hacer ningún tipo de discriminación entre personas de iguales condiciones (Corilloclla, 2009, p. 10).

Estos casos permiten observar que la intervención judicial en la etapa de definición del problema se presenta como una herramienta al servicio de los ciudadanos para lograr el «equilibrio» de la política, es decir, para forzar su cobertura, para lograr que su definición del problema contemple y abarque lo más posible las distintas concepciones de problema de los diversos actores. Así, la intervención judicial permite a aquellos actores interesados en participar en esta etapa, una vía para modificar o incidir en la construcción del problema. Por otro lado, al poder judicial le permite funcionar como un actor que envía mensajes a los diversos actores de la política, pues al tomar una cierta decisión, impone un estado de cosas, una concepción e interpretación que deberá ser respetada, así, después del fallo sobre VIH/SIDA antes mencionado, se espera que toda política relativa a la salud y tratamiento de este padecimiento contemple los efectos establecidos en la sentencia, en este caso, la cobertura universal.

En la tercera etapa, el diseño de la política o diseño o elaboración de la solución se puede entender como «el proceso mediante el cual las políticas son diseñadas, a través de análisis técnicos y procesos políticos, para alcanzar una meta en particular» (Birkland, 2015, p. 228). En esta etapa se construye la solución, y al hacerlo, se edifica el método por el cual se ajustará la política. Al respecto, Arias y Herrera plantean lo siguiente:

[se deben plantear] objetivos claros y precisos; se identifica la población objetivo: afectados y beneficiarios; se analizan las alternativas con sus respectivos efectos, tanto positivos como negativos; se relacionan los costos y los beneficios de las alternativas; y se elige la mejor opción. En esta etapa, como en todas las demás, es importante la participación de los beneficiarios de la política, pues contribuyen a revisar los objetivos y los modos de llevarlos a cabo (Arias y Herrera, 2012, p. 57).

Como se puede deducir, la influencia del sistema judicial en esta etapa se presenta de la mano de los efectos mencionados en las etapas anteriores. Determinar cuáles son las mejores alternativas de solución y cómo deben ser aplicadas, se puede concebir (con cierta razón) como una facultad casi exclusiva del poder ejecutivo con la participación marginal del legislativo, pero, como lo reflejan los casos antes mencionados y los resultados de estos a partir de las facultades exclusivas del sistema judicial, la participación de este tiene la capacidad para redirigir e incluso imponer una cierta forma de construir la política. Una resolución judicial que expone perfectamente los efectos enormes de la participación judicial en la etapa de diseño (y en todas las etapas), es el caso Brown vs Board of Education de 1954.

El caso Brown tuvo efectos tan grandes y significativos en el derecho estadounidense, que incluso un abogado llego a señalar que «para los afroamericanos, [Brown] divide la historia americana en B.C y A.D» (Theodore Shaw citado por Williams, 2004, p. 178). El caso en cuestión se remonta a una decisión de 1954 de la Corte Suprema de Estados Unidos, sin embargo, las raíces de la decisión y sus implicaciones se remontan a mucho antes, a finales del siglo XIX, específicamente a 1896, con el caso Plessy vs Ferguson, gracias al cual se acuño el principio de "separados pero iguales». En el caso Plessy, un hombre residente del Estado de Louisiana, «de raza mixta, en la proporción de siete octavos caucásico y un octavo de sangre africana» (Corte Suprema de Estados Unidos, 1896), desconozco cómo podrían determinar las «proporciones» de sangre en aquel entonces, en fin, la cuestión es que esta persona con un «octavo de sangre africana» intentó abordar un vagón de tren en primera clase, lo que estaba prohibido para los de su raza. Como resultado de su análisis, la Corte Suprema consideró que las leyes que dividían a blancos del resto era constitucional. Tendrían que pasar más de cincuenta años para que otro caso diera la oportunidad de revisar el principio «separados pero iguales». El caso Brown vs Board of Educatión, tiene relación con la negativa de la Corte Distrital de Kansas para permitir que una niña negra acudiera a una escuela de blancos. El resultado fue que la Corte suprema de Estados Unidos determinó lo siguiente: «concluimos que en el espacio de la educación pública la doctrina "separados pero iguales" no tiene lugar. Las instalaciones educativas separadas son inherentemente desiguales» (Williams, 2004, p. 178). Los efectos de esta resolución fueron incalculables, la decisión de la Corte Suprema de considerar como fundamentalmente desiguales a las escuelas y el esquema de «separados pero iguales», llevó al desmantelamiento del apartheid estadounidense. 
En pocas palabras, el Tribunal enviaba un mensaje a la sociedad en todos sus estratos, de que continuar con el estado de cosas violentaba lo dispuesto por la Constitución (catorceava enmienda), así, se hacía obvio que continuar construyendo, diseñando, implementado políticas bajo el esquema separatista sería anticonstitucional, y por ende, atacable judicialmente.

Esta resolución es un ejemplo de los efectos que una resolución judicial puede tener en el diseño e implementación de las políticas. Se entiende que a partir de que la Corte determina la forma en que habrá de explicarse y entenderse la realidad respecto a un tema en particular (educativo) todos deberán modificar lo necesario para adecuarse a esta, y quien no lo haga, se enfrenta al poder del Estado ${ }^{4}$.

Los efectos de las resoluciones judiciales en la cuarta etapa, la de implementación, se pueden observar a partir de los casos analizados anteriormente. La implementación se puede definir como «la capacidad de ejecutar, de llevar a cabo las acciones previstas para lograr los objetivos fijados en la etapa de diseño» (Arias y Herrera, 2012, p. 58). Por otro lado, Parsons define esta fase como «la continuación de la formulación de las políticas públicas por otros medios» (Parsons, 2007, p. 482). Lo que hay que resaltar de esta etapa, es que en ella se hacen evidentes los posibles errores o aciertos cometidos en las etapas anteriores, esto debido a que en la aplicación o ejecución, se refleja si lo que se planteó como objetivo se esta cumpliendo realmente. Como se puede deducir de los casos analizados con anterioridad, las decisiones judiciales tienen efectos muy amplios, por lo que una resolución puede afectar una o varias etapas del ciclo de políticas al mismo tiempo. Así mismo, envía un mensaje a los actores de las políticas, sobre todo en dos aspectos, el primero, que lo resuelto tiene efectos a considerarse en el diseño de las políticas, es decir, se deberán ajustar las políticas en proceso de diseño y las que están por diseñarse a lo dispuesto por la decisión judicial, y, segundo, que la obediencia a lo dispuesto en la resolución no es opcional, y cualquier intento de no aplicar o ajustar las políticas y su implementación a esta nueva realidad será combatida judicialmente y eventualmente eliminada o modificada, lo que implica que desconocer o ignorar lo dispuesto por los tribunales, puede terminar con un desperdicio de recursos, la modificación de la política o, en un caso más extremo, con su eliminación.

La etapa de evaluación y seguimiento esta presente en todo el ciclo de las políticas. Luis Aguilar menciona que esta etapa «cierra y abre el ciclo o espiral de la política» (Aguilar, 2010, p. 51). Se puede definir como "el uso de procedimientos sociales de investigación para de forma sistemática investigar la efectividad de la intervención de los programas sociales (Rossi, Freeman y Lipsey, 2004, p. 4). La evaluación esta presente a lo largo de todo el ciclo, o al menos debería estarlo, debido a que, para lograr una política diseñada con eficacia y verdaderas oportunidades de alcanzar los objetivos, se debe realizar una evaluación en cada una de las etapas para asegurar lo más posible, que se siguen los pasos adecuados o que se camina en la dirección deseada. Por ejemplo, en la etapa de formación de la agenda, grupos luchan por imponer su definición del problema, por capturar la atención gubernamental, por ello, se parte del supuesto de que los distintos actores ya evaluaron la situación y desarrollan la mejor estrategia para lograr sus objetivos, es decir, realizaron una evaluación previa. Igualmente, en la etapa de definición del problema, se espera que los actores de la política evalúen experiencias y efectos de políticas anteriores y cómo fue definido el problema, y si dicha definición se puede retomar, cambiar o debe ajustarse a la realidad actual, por otro lado, se debe evaluar a la población objetivo, conocerla y determinar sus características, etc., en la implementación se requiere, como ya mencioné, evaluar para conocer si los resultados obtenidos son los deseados, y de no serlo, modificar lo que haga falta. Como se pude observar, la evaluación trastoca cada una de las etapas, de no ser así, se camina a ciegas el sendero de la política. Pero ¿cómo se ve afectada esta última etapa por el sistema judicial? Para responder a esta pregunta, analizaré brevemente un caso emblemático de Argentina.

El caso Mendoza Beatriz Silva y otros contra Estado Nacional y otros s/ daños y perjuicios (en adelante caso Mendoza) sobre contaminación ambiental, presenta un ejemplo perfecto para conocer la influencia que puede tener el sistema judicial en todas las etapas de política pública, pero sobre todo, en la de evaluación. Este caso data del año 2004, en el que un grupo de personas demandaron ante la Corte Suprema de Argentina a cuarenta y cuatro empresas, con el objetivo de obtener indemnización por daños y perjuicios a con-

4 Un ejemplo de las consecuencias de no acatar las resoluciones judiciales es el caso de Orval Faubus, gobernador de Arkansas en 1957, quien se resistió a acatar la resolución de la Corte, impidiendo a un grupo de nueve estudiantes negros, conocidos después como «The Little Rock Nine», a ingresar a la preparatoria. Ante este panorama, el presidente de Estados Unidos Dwight D. Eisenhower, envió unidades del ejército al lugar, además de tomar el control de la Guardia Nacional de Arkansas, para imponer la resolución de la Corte. 
secuencia de la contaminación del río Matanza-Riachuelo, solicitando la restauración del medio ambiente. La resolución de la Corte Argentina fue muy extensa en cuanto sus implicaciones, en esta ocasión solo me enfocaré en los aspectos de la resolución respecto a la evaluación.

En su decisión, la Corte Argentina determinó que las empresas, así como las autoridades públicas eran responsables, cada una, de cumplir con ciertas cuestiones. A las empresas, les fue ordenado hacer pública su información sobre los procesos que contaminaban el río, cumplir con estándares internacionales en el tratamiento de residuos, colaborar con las autoridades, entre otros. A las autoridades, en este caso de todos los niveles, tanto municipal, estatal y federal (pues en ese espacio se conjuntaban las tres jurisdicciones), se les ordenó crear una política pública ${ }^{5}$, la cual sería evaluada por distintos actores, en especial la Universidad de Buenos Aires, la Defensoría del Pueblo y un cuerpo colegiado creado para la ocasión:

5. Habilitar la participación ciudadana en el control del cumplimiento del Plan de Saneamiento y del programa fijado en el presente. 6.- Encomendar al Defensor del Pueblo de la Nación la coordinación de dicha participación, mediante la conformación de un cuerpo colegiado en el que participarán los representantes de las organizaciones no gubernamentales que intervienen en esta causa en condición de terceros interesados (Corte Suprema de Justicia de la Nación Argentina, 2008, pp. 27-28).

Adicional a lo anterior, se contemplan medidas de apremio para garantizar el cumplimiento de la decisión:

Para medir el nivel de cumplimiento de esos objetivos la Autoridad de Cuenca deberá adoptar alguno de los sistemas internacionales de medición que se encuentran disponibles e informar al tribunal competente para la ejecución de esta sentencia en un plazo de 90 (noventa) días hábiles. El incumplimiento de la orden dentro del plazo establecido, importará la aplicación de una multa diaria a cargo del presidente de la Autoridad de Cuenca (Corte Suprema de Justicia de la Nación Argentina, 2008, p. 16).

La resolución, como se puede observar, no solo obliga a las autoridades a diseñar una política pública para resolver el problema (Plan de Saneamiento), sino que además, exige que dicho Plan contenga fechas de vencimiento para cada uno de los objetivos, así, al finalizar el tiempo contemplado para cada uno, y evaluado por el grupo de expertos, poder determinar si se cumplió con el objetivo o no, y en caso de que lo anterior sea negativo, imponer multas o medidas correctivas para garantizar la ejecución. Por lo tanto, esta resolución refleja perfectamente los efectos que puede tener el poder judicial en la evaluación.

\section{POLÍTICAS PÚBLICAS GLOBALES}

Para comprender el alcance de esta nueva aproximación a las políticas aún en construcción, debo primero explicar los efectos e influencia «heredados» de la gobernanza o la «nueva gobernanza» hacia la disciplina.

\subsection{De la gobernanza a la nueva gobernanza}

La gobernanza se entiende a partir de la capacidad del Estado para gobernar, es decir, de la capacidad y eficacia directiva del gobierno. Siguiendo a Aguilar (2014a), dos han sido las aproximaciones para abordar lo anterior: la gobernabilidad a partir de los años 70 y, la gobernanza, a partir de los años 90. La primera, toma forma a partir del texto de Samuel Huntington, Crozier y Watanuki, "La crisis de la democracia: reporte sobre la gobernabilidad de las democracias a la Comisión Trilateral", publicado en 1975 (Aguilar, 2014, p. 61). En este, los autores señalan como probable causa del futuro desgaste y crisis de la democracia a la forma de gobernar, y no al sistema político o económico. En pocas palabras, la capacidad que tenga o no el gobierno para gobernar a la sociedad depende únicamente de sus decisiones para mantener la estructura social y de gasto, es decir, en aquel tiempo (1975), el Estado de Bienestar imponía una fuerte carga fiscal y administrativa al Estado, lo que en la perspectiva de los autores, era insostenible, y terminaría por minar

5 La Corte ordenó a las autoridades crear lo siguiente: «un plan integrado que contemple un ordenamiento ambiental del territorio, el control sobre las actividades antrópicas, el estudio sobre el impacto ambiental de las empresas demandadas, un programa de educación ambiental y un programa de información ambiental» (Sentencia M. 1569. XL de 8 de julio, pp. 1-2). 
la capacidad del Estado para mantener la gobernabilidad y, en ultima instancia, llevaría a la sociedad a un colapso estatal y económico, así, en esta realidad tenía sentido, dice Aguilar, hablar de una dicotomía gobernabilidad/ingobernabilidad (Aguilar, 2014, p. 61). Si el gobierno no era capaz de ofrecer y resolver las demandas siempre crecientes de servicios y recursos por la sociedad, entonces se caería en una «ingobernabilidad».

La respuesta a esta aparente crisis fue la de «reconstruir» al Estado desde sus cimientos. El problema, se pensó, estaba en la forma en que estaba construido el Estado social, por lo tanto, se debían construir nuevas reglas, sobre todo en lo tocante a la relación mercado y Estado. La urgencia de pensar en estos cambios se hizo patente a partir de la crisis del Estado social de los setentas:

El acaecimiento de la crisis fiscal del Estado social (asistencial, de bienestar y seguridad social, desarrollador) y, en nuestros países, por arrastre, la crisis económica nacional, representó el vaticinio de la ingobernabilidad y puso de manifiesto la ingobernación, a saber, el hecho de que el gobierno había dejado de gobernar a su sociedad, por le menos en sentido económico, dado que la había conducido al estancamiento, la recesión o al hundimiento (...) y/o el hecho de que el gobierno se mostraba como un agente que carecía de la capacidad requerida para dirigir a su sociedad hacia objetivos positivos de bienestar y desarrollo, no obstante que se la había otorgado gran cantidad de poder y recursos para ese fin (Aguilar, 2014, p. 66).

Sin importar la poca rigurosidad en el análisis y conclusiones sobre el estancamiento económico, ni la poca discusión sobre los verdaderos efectos del gobierno y el sistema económico, se consideró que lo anterior era una oportunidad perfecta para comprobar la tesis expuesta por Huntington y otros, por ello, se llegó a la conclusión de que la respuesta estaba en democratizar el régimen político y en liberalizar la economía.

El enfoque de la gobernanza reaparece, dice Aguilar, en los años noventa, específicamente «en los documentos de dos organismos internacionales (BM, PNUD) y en la obra académica pionera coordinada por el holandés Jan Kooiman (1993): Modern Governance: New Government - Society Interactions» (Aguilar, 2014a, p. 15). La gobernanza tiene como característica principal, que reconoce que el Estado como ente único en la conducción del gobierno es imposible, pues no tiene la capacidad de conocer, decidir y dirigir todos los aspectos del conjunto social, así:

La conclusión es que, para estar en condiciones de conducir y coordinar a su sociedad, el gobierno requiere de los recursos de otros gobiernos (domésticos y extranjeros) y de los recursos de las organizaciones tanto del sector privado como de la sociedad civil (nacionales o multinacionales) (Aguilar, 2014a, p. 16).

Por lo tanto, la gobernanza se define como:

(...) el proceso de gobierno o de dirección de la sociedad. Se refiere al proceso por el cual o mediante el cual una sociedad se dirige, gobierna y gestiona a sí misma. Concretamente es el proceso a través del cual el gobierno, las empresas privadas, las organizaciones de la sociedad civil y los ciudadanos interactúan con el propósito de definir, acordar y decidir sus objetivos de interés y valor común, así como acordar y decidir las formas de organización, los recursos requeridos y las actividades a llevar a cabo para lograr los objetivos decididos (...) En suma, la gobernanza es proceso y estructura. Refiere al conjunto de valores, instituciones, normas y al conjunto de conocimientos y tecnologías, que orientan, regulan y sustentan las decisiones que el gobierno y la sociedad elaboran y toman para atender los asuntos públicos que importan y son decisivos para producir el orden social preferido, el tipo de sociedad preferido y constitucionalmente establecido y validado (Aguilar, 2014a, pp. 18-20).

Definida así, la gobernanza se puede entender en dos vertientes: la primera llamada «vieja gobernanza», «gobernanza por gobierno» o «gobernanza jerárquica», en la que el gobierno se presenta como el actor predominante y quien determina lo socialmente deseado, en contraste con una sociedad débil; la segunda es la «nueva gobernanza», "gobernanza por cogobierno» o «gobernanza moderna», que se caracteriza por que las decisiones sobre la conducción de la sociedad y el gobierno, ya no son resultado exclusivo de los designios de un gobierno solitario, sino más bien de una cooperación y sinergia entre diversos actores y organizaciones privadas y sociales (Aguilar, 2014a, pp. 21-22). En esta última, el gobierno no pierde su rol directivo, dice Aguilar, sino que lo ejerce de una forma más «holística», en cooperación con otros actores en un marco de legalidad y un modo más horizontal que vertical. 
Es este contexto de cambio y evolución en la titularidad del Estado como actor preponderante de las decisiones y realidad social, es que las políticas públicas se transforman. Si la gobernanza implica comprender que el Estado debe cogobernar con distintos actores privados y sociales así como transnacionales, entonces, las políticas, su diseño, ejecución y evaluación también habrán de modificarse y adaptarse a esta nueva realidad de responsabilidades compartidas, así, uno de los efectos más evidentes es que existen actores que trascienden las fronteras de los Estados y que influyen en las políticas, así, surge un interés por comprender los efectos globales en la disciplina.

\section{DEFINICIÓN Y CARACTERÍSTICAS DE LAS POLÍTICAS PÚBLICAS GLOBALES}

El interés por las políticas públicas globales surge, al igual que la gobernanza, en la década de los noventa. Destacan principalmente dos obras: Global Policy Studies and Peace Research (1990) de Marvin S. Soroos, y Global Public Policy (1997) de Wolfang Reinicke. Cronológicamente, quizá sea el artículo de Soroos en donde se menciona a las políticas públicas globales por primera vez. En su trabajo, él las define como aquellas «en las que todos los países pueden convertirse en partes. Así, las políticas globales son un subconjunto de las políticas internacionales que se definen por su potencial de universalidad» (Sooros, 1990, p. 118). La postura de este autor esta enmarcada sobre todo por la centralidad del Estado y la preminencia de la política exterior como origen y vehículo de las políticas globales, es decir, se caracteriza sobre todo por una concepción Estado-céntrica en detrimento de otros actores. A pesar de lo anterior, la conceptualización y reconocimiento de la existencia de políticas a nivel global es un paso importante en la construcción de este nuevo campo de estudio, pues anticipa la necesidad de trascender la dinámica local para responder ante los retos que se abren en ese futuro globalizador que adelantaba la última década del siglo XX.

La obra de Reinicke (1997) por otro lado, se enfoca en los efectos de la globalización en la soberanía de los Estados. El aspecto fundamental que intenta establecer su obra, es que la soberanía, entendida a partir de dos dimensiones: la soberanía externa (caótica y sin autoridad central) y una soberanía interna (en la que el Estado tiene el control sobre su territorio), es afectada por la globalización (económica), la que su vez impone nuevos actores en las dinámicas de las políticas, actores que no se rigen bajo las normas del Estado. En este escenario global predominantemente gobernado por los actores económicos, las políticas que importan deben construirse fuera y más allá de los márgenes del Estado, y nadie mejor para construirlas que los actores transnacionales (Reinicke, 1997, p. 132).

Las limitaciones, tanto de la obra de Soroos como de Reinicke, es que ambos se enfocan en el Estado como actor principal, así como en una sola dinámica de la globalización: la económica. Para ampliar este análisis, cuatro académicos se dieron a la tarea de enriquecer este nuevo acercamiento a las políticas, se trata de Diane Stone con al menos dos artículos: Global Public Policy: Transnational Policy Communities (2008) y Beyond the State: Global Policy and Transnational Administration (2019) en colaboración con Kim Moloney, Philip G. Cerny con Rethinking Wolrd Politics: a Theory of Transnational Neopluralism (2010) y William D. Coleman con Gobernance and Global Public Policy (2012).

La obra de Diane Stone de 2008, parte y reconoce las limitaciones presentes en la obra de Reinicke, por lo que propone la idea de «Agora global» (Stone, 2008), entendida como el lugar político, económico y social «neutral» que se presenta como disperso, fluido o incluso hasta caótico, en el cual distintos actores participan para definir las políticas globales. Quizá el mayor aporte de la obra de Stone es que reconoce a los actores relevantes de las políticas globales, que clasifica en tres grupos (Coleman, 2012; Stone, 2008): el primero compuesto por los «oficiales públicos internacionales» es decir, trabajadores del Estado que tienen en sus funciones la representación de su gobierno en discusiones de alcance global. El segundo grupo esta conformado por los «servidores públicos internacionales», integrados por los trabajadores de las organizaciones internacionales, y el tercer grupo es el de «profesionales de política transnacional», conformado por consultores, miembros de organizaciones no gubernamentales, académicos y científicos reconocidos, etc. Así, para Stone, las políticas globales están enmarcadas por la interacción de estos tres grupos (Coleman, 2012; Stone, 2008).

La propuesta de Philip Cerny por su parte, se enfoca en lo que él denomina como «neopluralismo transnacional» (Coleman, 2012; Cerny, 2010), que en esencia se refiere a la pluralidad de actores que participan en la definición y dirección de las políticas, es decir, desplaza la discusión más allá del Estado como actor clave y otorga a otros actores un rol importante. Siguiendo esta línea, Cerny amplía el «triángulo de hierro», utilizado en la academia estadounidense para estudiar a las políticas, el cual incluye a tres actores princi- 
pales: la rama ejecutiva, el congreso (legislativa) y los grupos de interés. Lo que el autor propone a partir del análisis de Stone, es incluir a dos actores más: los oficiales públicos internacionales y al sector privado transnacional, este último de acuerdo con Coleman, equivalente al grupo de profesionales de política transnacional (Coleman, 2012, p. 8). Así, el triángulo se transformaría en un pentagrama de actores de la política pública global.

Ahora, en cuanto a las características de las políticas públicas globales, William D. Coleman enlista tres: 1. Problema global, 2. Proceso de decisión policéntrica y 3. Fronteras difusas de actuación (Coleman, 2012, pp. 10-13). La primera se enfoca en señalar que el problema presenta una dimensión global, de ahí que una política pública diseñada desde y para un Estado no sea suficiente para resolver el problema. Al respecto, el autor señala tres ejemplos, reconocimiento de comunidades indígenas (territorios, lenguaje, cultura, etc.), efectos climáticos y, problemas similares que surgen al mismo tiempo en diversas partes del mundo. La segunda, la decisión policéntrica, refuerza lo expuesto por Stone y Cerny, al señalar la característica policéntrica de la decisión en políticas, es decir, espacios en donde los diversos actores (tres de Stone y pentagrama de Cerny) interactúan. En la tercera, se refiere a problemas en los cuales no esta claro el nivel de participación de cada uno de los actores involucrados, así como tampoco el grado de responsabilidad de estos, por lo que la estrategia de solución se presenta compleja y plural.

Finalmente, el artículo de Diane Stone en colaboración con Kim Moloney, ofrecen una definición de políticas globales como.

(...) una serie de procesos entrelazados pero inconexos de deliberación y cooperación públicoprivada entre por un lado oficiales con base en el Estado y organizaciones internacionales y actores no estatales por el otro, alrededor del establecimiento de normas comunes y agendas políticas para asegurar la entrega de bienes públicos globales o mejorar los problemas transnacionales (Moloney y Stone, 2019, p. 107).

En suma, la discusión actual de la disciplina parece enforcarse casi exclusivamente en los actores principales, la forma en que interactúan y la posición del Estado respecto a estos. Por lo anterior, parece ser que la intervención judicial en las políticas públicas no es un tema desarrollado en su dimensión global.

\subsection{Políticas públicas globales e intervención judicial}

Establecido lo anterior ¿Cómo pueden interactuar el sistema judicial y las políticas públicas globales? Una cuestión que no ha sido abordada por los estudios antes mencionados es justamente la forma, extensión e implicaciones entre políticas globales y sistema judicial, por lo que las aportaciones que daré a continuación son provisionales y aún están en construcción.

Algo que tienen en común las posturas desde Soroos (1990) hasta Moloney y Stone (2019), es que actores transnacionales ascienden en la dinámica internacional reclamando más atención e influencia en las negociaciones y decisiones globales, actores que no están limitados y definidos por una realidad fronteriza. Considero que, entre estos actores, se olvida la enorme influencia que pueden tener los tribunales de alcance internacional, como por ejemplo la Corte Interamericana de Derechos Humanos (CIDH), la Corte Penal Internacional o la Corte Europea de Derechos Humanos.

Ya he establecido que el sistema judicial fruto de sus facultades exclusivas, presenta al menos cuatro efectos en las políticas: vetar o reafirmar decisiones, actor proactivo, árbitro imparcial y representante de la sociedad. Estos efectos, como se ha observado en el análisis de los casos anteriores, afectan al ciclo de las políticas, ahora, cabría preguntarse si dichos efectos pueden venir también de un tribunal internacional, es decir, de un actor no contemplado en los estudios de políticas globales y que, por el nivel de influencia de sus decisiones, tiene la capacidad de incidir en las políticas de un país, o incluso de varios sometidos a su jurisdicción. La respuesta a lo anterior es que sí, un tribunal internacional puede, desde su ámbito de competencia incidir en las políticas públicas de uno o varios países, lo que lo hace un actor que merece ser contemplado en el estudio de políticas globales. Para sustentar lo anterior, a continuación, analizaré tres casos paradigmáticos resueltos por la Corte Interamericana de Derechos humanos: Radilla Pacheco vs México (Caso Radilla) sobre desaparición forzada, González y otras («Campo Algodonero») vs México sobre asesinato de mujeres, y Castañeda Gutman vs México sobre representación política electoral. Todos estos casos resaltan entre otras cosas, por los efectos tan grandes que dichas resoluciones tuvieron para el Estado mexicano, en particular por los cambios que introdujeron en su legislación y políticas. 
Rosendo Radilla Pacheco, fue un líder social del municipio de Atoyac de Álvarez, Guerrero, quien, en 1971 , fue detenido ilegalmente en un reten militar, quien lo ingresó en un cuartel de la misma localidad, donde fue visto por última vez. Ante la falta de respuesta y resultados por parte de las autoridades mexicanas, en el año 2001, se presentó ante la Comisión Interamericana el caso, quien a su vez demandó al Estado mexicano por su inacción ante las recomendaciones emitidas en el año 2008 ante la Corte Interamericana, quien emitiría su sentencia en el año 2009. En dicha sentencia, determinó, entre otras cosas que:

\begin{abstract}
El Estado deberá adoptar en un plazo razonable, las reformas legislativas pertinentes para compatibilizar el artículo 215 A del Código Penal Federal con los estándares internacionales en la materia...El Estado deberá conducir eficazmente, con la debida diligencia y dentro de un plazo razonable la investigación y, en su caso, los procesos penales (Corte Interamericana de Derechos Humanos, 2020b).
\end{abstract}

Como es evidente, la Corte impone el deber de legislar, pero no como de forma libre, sino acotándolo a los estándares internacionales, es decir, le indica los parámetros y supuestos que debe cumplir y contemplar. Igualmente, impacta en los procesos de impartición de justicia, lo que sin lugar a dudas, impacta en las políticas públicas de seguridad que hasta ese momento se implementaban, sobre todo en temas de desaparición forzada. Pero quizá el efecto e influencia más grande de la resolución en las políticas públicas en México, es que sentó las bases para la reforma en materia de derechos humanos en $2011^{6}$, la cual modificó la redacción del artículo $1^{\circ}$ de la Constitución mexicana, donde «queda establecido con claridad que el Estado únicamente reconoce derechos, los cuales son universales e inherentes al ser humano, desterrando en forma definitiva cualquier pretensión de concebirlos como otorgados o limitados por la acción estatal» (Lara, 2015, p. 68). Esta reforma tuvo efectos enormes y quizá incalculables para el sistema jurídico mexicano, así como para las políticas públicas, pues a partir de esta, el principio pro persona sería «la guía de interpretación y aplicación de las normas relativas a los derechos humanos» (Lara, 2015, p. 69), por lo tanto, toda política era susceptible de ser evaluada y confrontada con dicho principio, y en caso de no cumplirlo, podría ser combatida judicialmente. Por otro lado, esta reforma, fruto de la resolución de la Corte Interamericana, tuvo como efecto no solo el cambio de legislación, criterios y principios, sino también la forma en que se llevaban los litigios (sobre todo aquellos en los que se argumentaba alguna violación a derechos humanos, como los judicios para proteger derechos económicos, sociales y culturales), así, un abogado, a través de litigio estratégico, podía fundamentar sus pretensiones en criterios internacionales, exigiendo un espectro de protección más amplio, con lo que podía garantizar una protección a los derechos humanos más «extensa» que la que el propio sistema local le permitía. Como se puede observar, una resolución de un tribunal internacional fue el detonante para un cambio estructural de enormes proporciones para el sistema jurídico mexicano, con ello, los estándares bajo los cuales las políticas públicas se concebían, aplicaban y evaluaban cambió radicalmente.

El segundo caso paradigmático que impactó al Estado mexicano fue González y otras vs México, mejor conocido como «Campo Algodonero», resolución que fue emitida por la CIDH en 2009. El caso y su respectiva resolución fijaron un antes y un después en materia de violencia contra las mujeres en México.

La violencia feminicida, definida por Marcela Lagarde como «la culminación de múltiples formas de violencia de género (contra las mujeres) que atentan contra sus derechos humanos y las conducen a variadas formas de muerte violenta, y (que) son toleradas por la sociedad y el Estado» (Lagarde, 2012, citado por Van Scoit, 2019), fue una realidad constante en Ciudad Juárez, México, donde desde 1994 hasta 2002, se habían presentado al menos 189 asesinatos de mujeres. El 11 de noviembre de 2001, se encontraron en un campo algodonero de dicha ciudad, ocho cuerpos de mujeres, lo que desencadenó una campaña para esclarecer los asesinatos, la cual fue secundada por más de trescientas organizaciones. Ante la indiferencia de las autoridades, Irma Monreal, Benita Monárrez y Josefina González presentaron una petición formal ante la CIDH en 2002 (Van Scoit, 2019, p. 5).

En la resolución emitida por la CIDH, se determinó, además de solicitar cambios a la legislación, que.

(...) se deberá remover todos los obstáculos de jure o de facto que impidan la debida investigación de los hechos y el desarrollo de los respectivos procesos judiciales... la investigación deberá incluir una perspectiva de género; emprender líneas de investigación específicas

6 Al respecto de la relevancia del caso Rosendo Radilla para el estado mexicano véase: https://www.cndh.org.mx/noticia/rosendo-radilla-pacheco-desaparicion-forzada 
respecto a violencia sexual, para lo cual se deben involucrar las líneas de investigación sobre los patrones respectivos en la zona; realizarse conforme a protocolos y manuales que cumplan con los lineamientos de esta Sentencia (Corte Interamericana de Derechos Humanos, 2020c).

Esta resolución impactó no solo en la forma en que dicho caso en específico se condujo, ni como lo habrían de hacer otros en el futuro (investigación, protección, reparación del daño, etc.), sino que se establecieron criterios en materia de «prevención» (lo que se conoce hoy como el «deber de prevenir» de los Estados) el cual, si bien no esta contemplado expresamente en la Convención Americana sobre Derechos Humanos, esta documentado en el desarrollo jurisprudencial de la Corte (Silva, 2016, p. 3). Este desarrollo no fue resultado de una solo resolución, sino de varias a lo largo del tiempo (Silva, 2016), lo que permitió construir criterios que determinarían una serie de condiciones con las cuales deberá cumplir el Estado sujeto a la jurisdicción de la CIDH, en específico, el deber de prevención abarca «todas aquellas medidas de carácter jurídico, político, administrativo y cultural que promuevan la salvaguarda de los derechos humanos y que aseguren que las eventuales violaciones a los mismos sean efectivamente consideradas y tratadas como un hecho ilícito» (Van Scoit, 2019, p. 7). Este deber, así como lo establecido en la resolución, implican para México, el deber de diseñar, implementar y evaluar políticas públicas que permitan disminuir o eliminar las condiciones que provocan la violencia contra las mujeres, de ahí que esta resolución haya tenido un impacto tan profundo en las políticas públicas en materia de género.

El eco de esta resolución en el sistema jurídico y político mexicano fue incalculable, pero al menos podemos citar algunos cambios específicos que se dieron como resultado de esta resolución: la publicación en 2007 de la Ley Estatal del Derecho de las Mujeres a una Vida Libre de Violencia, para el Estado de Chihuahua (pronto otros Estados de la República adoptarían leyes similares), un mes después, se aprobó la Ley General de Acceso para las Mujeres a una Vida Libre de Violencia, en la que se incluye la definición de violencia feminicida, así como la figura de Alerta de Violencia de Género Contra las Mujeres (Van Scoit, 2019, p. 8).

Como se puede observar, esta resolución redefinió la forma y contenido de las políticas públicas en materia de género, amplió y enriqueció el catálogo jurídico en la materia, así como también la forma y estructura de los procedimientos judiciales, como se puede apreciar en la propia redacción de la CIDH:

En este sentido se pretende que las reparaciones tengan un efecto no sólo restitutivo sino también correctivo, y por tanto borda sobre la necesidad de tomar medidas estructurales para resolver el problema de origen, destacando por ejemplo el hecho de que deba generarse un programa de educación dirigido a la población de Chihuahua, esto con la finalidad de superar los estereotipos sobre el rol social de las mujeres y dejar atrás los patrones de discriminación y violencia sistemáticos, así como evitar los homicidios de mujeres por razones de género (Rangel, 2011, p. 169).

Las resoluciones de la CIDH a los casos hasta ahora analizados, ejemplifican el interés de la Corte por ir más allá de la mera resolución del caso concreto, es decir, se puede observar como estas resoluciones buscan ante todo «corregir» las condiciones que provocan los problemas sometidos a su consideración, de ahí que sus resoluciones se ocupen no solo de imponer al Estado mexicano legislar, sino también, modificar conductas, diseñar estrategias para modificar ciertos patrones, etc., todo lo cual no sería posible sin el diseño de políticas públicas.

El último caso al que quisiera referirme por su impacto en las políticas públicas es el caso Castañeda Gutman vs México (caso Castañeda). En el año 2004, Jorge Castañeda Gutman, presentó ante el entonces Instituto Federal Electoral su solicitud de registro como candidato independiente a la presidencia de México. El registro fue negado, lo que dio lugar a los medios de impugnación disponibles por parte de Castañeda, que una vez agotados, dieron pie a la presentación del caso ante la Comisión Interamericana y posteriormente a la Corte Interamericana en 2007 (Pelayo y Vázquez, 2009).

En su resolución, la CIDH determinó que «El Estado debe, en un plazo razonable, completar la adecuación de su derecho interno a la Convención, de tal forma que ajuste la legislación secundaria y las normas que reglamentan el juicio de protección de los derechos del ciudadano...» (Corte Interamericana de Derechos Humanos, 2020a). La decisión allanaría el camino para que, en el año 2012, se realizará una «reforma política» incluyendo en la Constitución el derecho de los ciudadanos a ser registrados como candidatos independientes (Campos, 2014, p. 65). 


\section{CONCLUSIONES}

La intervención judicial en políticas públicas se pude presentar en cuatro formas fundamentales derivadas de sus facultades exclusivas dentro de un sistema de control constitucional: vetar o reafirmar decisiones, actor proactivo, árbitro imparcial y representante de la sociedad. Estas a su vez, producen efectos en las cinco etapas del ciclo de políticas públicas identificadas en este trabajo: formación o ingreso a la agenda, definición del problema, diseño de la política, implementación y seguimiento y evaluación. Del análisis de las etapas y de los casos reales propuestos como ejemplo para cada una, se pudo observar que las resoluciones judiciales impactan de diversas formas y con diversa intensidad, así, los efectos van desde modificar la implementación de una política ya en curso, imponer una cierta forma de construirla, o incluso solicitar la creación de una desde cero, con fechas y plazos de entrega, pero sobre todo, uno de los efectos que todos los casos tienen en común, es que sientan precedentes, es decir, dejan un «camino» que otros (abogados, personas afectadas/ interesadas, etc.) pueden seguir para obtener los mismos resultados, igualmente, estos precedentes envían mensajes a los actores de las políticas, pues ya sea de forma intencional o no (judicial politics), una resolución deja huella en el sistema jurídico, esto implica que un tribunal de jerarquía constitucional, al resolver un caso y determinar la forma en que debe interpretarse un tema, marca la pauta a seguir para las futuras políticas que tengan relación con el tema, como lo ejemplificó el caso Brow vs Board of Education.

A pesar de que se trata de una disciplina aún en construcción, las características y alcances de las políticas públicas globales parecen tener al menos dos elementos fundamentales en los cuales coinciden los investigadores, primero, que los actores involucrados en su diseño y ejecución van más allá del Estado (actores identificados por Stone y pentagrama de Cerny) y, segundo, que tratan temas que, por su importancia, trascienden la territorialidad del Estado (cambio climático, migración, refugiados, etc.), por lo que se requieren soluciones y definiciones transnacionales. Ahora, la intervención judicial en esta disciplina no se presenta en la forma de interacción o discusión entre los actores mencionados, sino más bien, de una forma directa a partir de las resoluciones, así, se trata de tribunales internacionales que impactan en políticas locales o nacionales, pero que, gracias a su jurisprudencia, impactan a diversos países, lo que implica un alcance transnacional de sus decisiones y nivel de influencia. Derivado de lo anterior, considero que los estudios actuales de la disciplina olvidan a los tribunales internacionales como actores importantes en la disciplina, quienes en sí mismos, ya poseen una representación internacional, pues los jueces son elegidos de entre los Estados miembros, igualmente, sus decisiones, fruto de esta representatividad, generan precedentes que van más allá de las fronteras de los Estados. Por lo tanto, propongo incluir al análisis de actores de Stone, así como el de Cerny, a tribunales internacionales como la Corte Interamericana de Derechos Humanos, el Tribunal Europeo de Derechos Humanos, la Corte Penal Internacional y, en general, considerar al sistema judicial como un actor importante en las políticas públicas, no solo nacionales sino globales.

Los casos resueltos por la CIDH nos permiten observar el enorme efecto que tienen estas resoluciones en el entramado jurídico, político y social de un país, así como en el diseño, implementación y evaluación de sus políticas públicas. Lo que quiero resaltar con estos casos, es que si bien la literatura sobre políticas globales concibe a esta como fruto de la construcción de actores internacionales para resolver problemas que trascienden fronteras, en el caso de los tribunales internacionales, específicamente la CIDH, vemos como una corte internacional se pronuncia sobre un caso local, el cual, gracias a su jurisprudencia, puede generar cambios no solo en el país demandado, sino también en otros países, a través de por ejemplo litigio estratégico que retome los argumentos y postulados vertidos en cada caso (obligación de prevenir de los Estados). Considero que los tribunales internacionales deben ser considerados actores de las políticas públicas globales, para lo cual, propongo en el caso de Stone, cuatro actores relevantes de las políticas globales: a) oficiales públicos internacionales, b) servidores públicos internacionales, c) profesionales de la política transnacional y d) tribunales internacionales. En el caso de Cerny, pasar de un «pentagrama» a un «hexagrama» de actores de la política pública global, quedando como sigue: a) rama ejecutiva, b) rama legislativa, c) grupos de interés, d) oficiales públicos internacionales, e) sector privado internacional y f) tribunales internacionales.

Finalmente, la participación del sistema judicial en las políticas, así como en su variante global, puede tener efectos muy claros y directos, que pueden derivar en cambios importantes, así como en la creación o terminación de estas, sin embargo, sus efectos y alcances aún merecen mayor análisis. Si bien la participación judicial puede tener efectos benéficos para las políticas, sobre todo en casos que requieran soluciones rápidas (como en derechos humanos, acceso a la salud, medicamentos, etc.), también tiene limitaciones importantes, como por ejemplo los tiempos de resolución (sobre todo para que llegue a tribunales interna- 
cionales), los alcances de la decisión, que por lo general se abocan a la persona que lo promueve (excepto cuando sienta precedentes o jurisprudencia) o, que el hecho de acudir a las instancias judiciales puede implicar, casi por definición, una ausencia de efectividad por parte de los poderes ejecutivo y legislativo par dar solución a varios problemas. Por lo tanto, se trata de un campo de estudio aún en construcción, cuyos límites, implicaciones y alcances esperan ser definidos y desarrollados.

\section{REFERENCIAS BIBLIOGRÁFICAS}

Ackerman, B. (2006). El surgimiento del constitucionalismo mundial. Criterio jurídico, 1(6), 9-35. https://revistas. javerianacali.edu.co/index.php/criteriojuridico/article/view/251

Aguilar, L. (2010). Política pública. Siglo XXI Editores.

Aguilar, L. (2014). Gobernanza y gestión pública. Fondo de Cultura Económica.

Aguilar, L. (25 de marzo de 2014a). La nueva gobernanza pública [Cátedra Magistral: la gobernanza de los asuntos públicos: Centro de Gobernanza Pública y Corporativa] (pp. 1-38). Universidad del Turabo. https://gurabo.uagm. edu/sites/default/files/uploads/Centro-Gobernanza/CATEDRAL_ANUAL/La-Nueva-Gobernanza-Publica.PR.UT.pdf

Aguiar, A. (2019). Gobierno y política judicial en México. Editorial Fontamara.

Arellano, D. y Blanco, F. (2013). Políticas públicas y democracia. Instituto Federal Electoral. https://portalanterior. ine. mx/archivos3/portal/historico/recursos/IFE-v2/DECEYEC/EducacionCivica/CuadernosDivulgacion/ CuadernosDivulgacion-pdfs/CUAD_30_definitivo.pdf

Arias, D. y Herrera, H. (2012). Entre políticas gubernamentales y políticas públicas. Análisis del ciclo de las políticas de desarrollo del gobierno del Estado de Michoacán, 2003-2010. Instituto Nacional de Administración Pública. http:// ru.juridicas.unam.mx/xmlui/handle/123456789/13355

Bardach, E. (2012). A practical guide for policy analysis: the eightfold path to more effective problem solving. Sage.

Birkland, T. (2015). An introduction to the policy process: theories, concepts, and models of public policy making. Routledge.

Campos, S. (2014). Las candidaturas independientes en México. Revista Derecho del Estado, 33, 65-99. https:// revistas.uexternado.edu.co/index.php/derest/article/view/3957

Carmona, U. (2007). La división de poderes y la función jurisdiccional. Revista Latinoamericana de Derecho, IV(7-8), $175-211$.

Carpizo, J. (2009). El tribunal constitucional y el control de la reforma constitucional. Boletín Mexicano de Derecho Comparado, 125, 735-794. http://www.scielo.org.mx/pdf/bmdc/v42n125/v42n125a6.pdf

Celeste, C. (2013). La función de los tribunales constitucionales y la eficacia de sus sentencias a la espera de un caso emblemático. En E. Alonso (coord.), Estudios de derecho público. (pp. 75-85). Asociación de Docentes, Facultad de Derecho y Ciencias Sociales, Universidad de Buenos Aires. http://www.derecho.uba.ar/docentes/pdf/estudiosde-derecho/001-edp-danesi.pdf

Cepeda, M. y Montealegre, E. (coords.) (2007). Teoría constitucional y políticas públicas: bases críticas para una discusión. Universidad Externado de Colombia.

Cerny, P. (2010). Rethinking world politics: a theory of transnational neopluralism. Oxford University Press.

Cervantes, L. (1996). Los tribunales constitucionales en el derecho comparado. Un estudio introductorio sobre sus antecedentes y situación jurídica actual. En A. Cancado, C. Moyer y C. Zeldon, Estudios básicos de derechos humanos VI. Instituto Interamericano de Derechos Humanos (pp. 355-389). https://www.iidh.ed.cr/IIDH/ media/2245/estudios-basicos-06-1996.pdf

Coleman, W. (2012). Governance and global public policy. En D. Levi (ed.), The Oxford Handbook of Governance. Oxford University Press.

Corilloclla, P. (2009). La justicia constitucional y las políticas públicas: una aproximación. Universidad Diego Portales.

CORTE INTERAMERICANA DE DERECHOS HUMANOS (2020a). Castañeda Gutman vs. México [ficha técnica]. Fecha de consulta: 16-09-2020. https://www.corteidh.or.cr/cf/jurisprudencia2/ficha_tecnica.cfm?nld_ Ficha=298\&lang=

CORTE INTERAMERICANA DE DERECHOS HUMANOS (2020b). Radilla Pacheco vs. México [ficha técnica]. Fecha de consulta: 16-09-2020. https://www.corteidh.or.cr/CF/jurisprudencia2/ficha_tecnica.cfm?nld_Ficha=360

CORTE INTERAMERICANA DE DERECHOS HUMANOS (2020c). González y otras ("Campo Algodonero») vs. México [ficha técnica]. Fecha de consulta: 16-09-2020. https://www.corteidh.or.cr/cf/Jurisprudencia2/ficha_tecnica. $\mathrm{cfm}$ ?nld_Ficha $=347 \&$ lang=es

CORTE SUPREMA DE ESTADOS UNIDOS (1896). Plessy v. Ferguson. Cornell Law School: Legal Information Institute. Fecha de consulta: 16-09-2020. https://www.law.cornell.edu/supremecourt/text/163/537

CORTE SUPREMA DE JUSTICIA DE LA NACIÓN ARGENTINA (8 de julio de 2008): Mendoza, Beatriz Silva y otros c. Estado Nacional y otros s/ daños y perjuicios (daños derivados de la contaminación ambiental del Rio MatanzaRiachuelo) (expediente M. 1569. XL). Fecha de consulta: 17-09-2020. https://www.escr-net.org/es/caselaw/2011/ mendoza-beatriz-silva-y-otros-c-estado-nacional-y-otros-s-danos-y-perjuicios-danos 
Dery, D. (2000). Agenda setting and problem definition. Policy Studies, 21(1), 37-47. https://doi. org/10.1080/014428700114008

Dye, T. (2013). Understanding public policy. Pearsons Education.

Everett, S. (2003). The policy cycle: democratic process or rational paradigm revisited? Australian Journal of Public Administration, 62(2), 65-70. https://doi.org/10.1111/1467-8497.00325

Fernández, J. (1999). La expansión de la justicia constitucional en Europa central y oriental. Ius et Praxis, 5(2), $321-352$.

Fix-Zamudio, H. (2002). Breves reflexiones sobre la naturaleza, estructura y funciones de los organismos jurisdiccionales especializados en la resolución de procesos constitucionales. En J. Vega y E. Corzo (coords.), Tribunales y justicia constitucional. Memoria del VII Congreso Iberoamericano de Derecho Constitucional (pp. 201238). Universidad Nacional Autónoma de México. Instituto de Investigaciones Jurídicas. http://ru.juridicas.unam. $\mathrm{mx} / \mathrm{xmlui} / \mathrm{handle} / 123456789 / 16159$

Howlett, M. (2019). Moving policy implementation theory foward: a multiple streams/critical juncture approach. Public Policy and Administration, 34(4), 405-430. https://doi.org/10.1177/0952076718775791

Lara, R. (2015). La reforma de derechos humanos de 2011: hacia el estado constitucional. En M. Carbonell, H. Fix, L. R. González y D. Valadés (coords.). Estado constitucional, derechos humanos, justicia y vida universitaria: estudios en homenaje a Jorge Carpizo. Derechos humanos (tomo V, vol. 2, pp. 65-78). https://biblio.juridicas. unam.mx/bjv/detalle-libro/3977-estado-constitucional-derechos-humanos-justicia-y-vida-universitaria-estudios-enhomenaje-a-jorge-carpizo-derechos-humanos-tomo-v-vol-2

Miranda, M. (2018). El tribunal constitucional y el rol del juez constitucional. Lex, 22. 85-100. http://revistas.uap.edu.pe/ ojs/index.php/LEX/article/view/1650

Moloney, K. y Stone, D. (2019). Beyond State: global policy and transnational administration. International Review of Public Policy, 1(1), 104-118. https://doi.org/10.4000/irpp.344

ORGANIZACIÓN DE LAS NACIONES UNIDAS (2020). ¿Qué es el Estado de Derecho? Fecha de consulta: 17-092020. https://www.un.org/ruleoflaw/es/what-is-the-rule-of-law/

Parsons, W. (2007). Políticas públicas: una introducción a la teoría y la práctica del análisis de políticas públicas. FLACSO.

Pelayo, C. y Vázquez, S. (2009). El caso Castañeda ante la Corte Interamericana de Derechos Humanos. Anuario Mexicano de Derecho Internacional, 1(9). https://doi.org/10.22201/iij.24487872e.2009.9.311

Rangel, L. (2011). Sentencias condenatorias al Estado mexicano dictadas por la Corte Interamericana de Derechos Humanos y sus implicaciones en el orden jurídico nacional. IUS Revista del Instituto de Ciencias Jurídicas de Puebla, 28, 160-186. https://doi.org/10.35487/rius.v5i28.2011.69

Reinicke, W. (1997). Global public policy. Foreign Affairs, 76(6), 127-138. https://www.foreignaffairs.com/ articles/1997-11-01/global-public-policy

Rossi, P., Freeman, H. y Lipsey, M. (2004). Evaluation a systematic approach. Sage Publications.

Silva, M. (2016). El "deber de prevenir» violaciones a los derechos humanos y algunas de sus posibles consecuencias. Revista de derecho y ciencias penales: Ciencias Sociales y Políticas (Universidad San Sebastián, Chile), 22, 545-570.

Soroos, M. (1990). Global policy studies and peace research. Journal of Peace Research, 27(2), 117-125. https://doi. org/10.1177/0022343390027002002

Stone, D. (2008). Global public policy: transnational policy communities and their networks. Policy Studies Journal, 36(1), 19-38. https://doi.org/10.1111/j.1541-0072.2007.00251.x

Stone, D., Maxwell, S. y Keating, M. (2001). Bridging research and policy. An International Workshop. UK Department for International Development Radcliffe House, Warwick University. https://warwick.ac.uk/fac/soc/pais/research/ researchcentres/csgr/research/keytopic/other/bridging.pdf

UNITED STATES SUPREME COURT (1896). Plessy vs Ferguson. Cornell Law School. Legal Information Institute. Fecha de consulta: 17-09-2020. https://www.law.cornell.edu/supremecourt/text/163/537

Van Scoit, G. (2019). El caso de campo algodonero: acercamientos alternativos al dolor social [Ensayo. Mención especial Décima Edición Concurso «Género y Justicia» 2019]. Fecha de consulta 27-02-2021. https://www.scjn. gob.mx/sites/default/files/igualdad-genero/2019-11/MENCION_ESPECIAL_869_el-caso-de-campo-algonoderoacercamientos-alternativos-al-dolor_social.pdf

Velásquez, R. (2009). Hacia una nueva definición del concepto «política pública», Desafíos, 20, 149-187. https:// revistas.urosario.edu.co/index.php/desafios/article/view/433

Williams, N. (2004). Brown v. Board of Educaction fifty years later: what makes for greatness in a legal opinión? Loyola University Chicago Law Journal, 36, 177-199. https://lawecommons.luc.edu/facpubs/248/ 